\title{
Interpretar e traduzir a língua dos Smurfs
}

\author{
Ronaldo Lima e Gisele Tyba Mayrink Redondo Orgado
}

\begin{abstract}
Resumo: Aborda-se neste artigo a obra L'Histoire de Schtroumpfs de Pierre Culliford (1980/1958) à luz da Teoria Interpretativa proposta por Lederer \& Seleskovitch (1989). Põem-se em evidência usos semióticos e linguísticos empregados pelo autor para pôr em operação processos de natureza interpretativa e tradutológica. A obra atrai o leitor para os jogos lexicais que o incitam à busca por significações aparentemente omitidas nos textos. A troca de sentido entre as modalidades semióticas verbal e não-verbal age como recurso-chave para a resolução dos falsos entraves estrategicamente colocados no texto. As manipulações realizadas sobre as conexões intertextuais e intersemióticas (i.e. verboimagéticos) permitem ao leitor preencher, com unidades lexicais plenas, os "falsos-gaps". Esses recursos de caráter lúdico e pedagógico, presentes no original em francês, foram suprimidos nas traduções para outros idiomas. O objetivo desta investigação é retomar a proposta inicial de Culliford, demonstrando como esses artifícios se processariam em português.
\end{abstract}

Palavras-chave: leitura, tradução, interpretação, histórias em quadrinhos, literatura.

\section{Interpretando a língua schtroumpf}

A obra L'Histoire de Schtroumpfs ${ }^{1}$ de Pierre Culliford (1980/1958) é composta por uma série de Histórias em Quadrinhos (HQs), lançadas com o objetivo de contemplar leitores de todas as idades. Além dos com-

Considerando-se que a obra será estudada a partir da versão francófona original, decidiu-se traduzir "Les Schtroumpfs" por "Os Estrunfes", muito embora essa obra tenha se tornado conhecida no Brasil por sua denominação em inglês. Quem não se lembra de Os Smurfs veiculados nos anos 1980 em forma de desenhos animados? 
ponentes apontados por Umberto Eco (2000), de natureza histórico-cultural, capazes de seduzir o leitor adulto e exigente, os Schtroumpfs também atraem o público jovem pelas características de suas carismáticas personagens. As pequenas criaturas azuis formam uma sociedade alternativa que vive de forma simples e pacífica. Constituem um grupo com características singulares, mas com diferenças físicas pouco marcadas. Tal uniformidade remete o leitor às categorias de base, inerentes ao universo das crianças. Neste escopo não há, conforme Brito (2003), poderes que imponham estratificações e hierarquias, nem sobre as expressões estéticas, nem sobre os componentes que constituem a língua, tal como o léxico. Doravante, a palavra do texto schtroumpf se torna como aquela do dicionário imaginado por Georges Bataille (1929) descrita em seu texto Informe. A palavra serve tão somente como sustentáculo. Não denota, não oferece significação estanque, apenas dispõe-se às necessidades que se possa ter dela. Segundo Bataille (ibidem): "um dicionário passaria a existir a partir do momento em que não oferecesse mais a significação das palavras, mas seus usos efetivos" (tradução dos autores). ${ }^{2}$

Para contemplar o máximo de leitores, o autor reúne em suas HQs os elementos fantásticos em geral presentes nas fábulas e nos contos, dos quais trata Nelly Novaes Coelho (1991). Culliford faz renascer, sob outras roupagens, as velhas fórmulas que envolvem o mundo mágico dos gnomos, das terras encantadas que lembram a Lilliput de Jonathan Swift (1667-1745) em sua obra Gulliver's Travels (1726/35, cf. 1996). Em arte sequencial bidimensional, Culliford compõe seus textos e imagens imbricados. Prega a convivência pacífica entre os povos através do compartiIhamento de uma espécie de esperanto, de uma língua adâmica. Uma forma de comunicação que restitua à humanidade o entendimento que havia na imaginada sociedade d'avant-Babel, na qual todos os povos se entendiam através de um só código. Embora se trate, naturalmente, de uma simulação em forma de jogo.

Ao colocar a língua no centro da questão, Culliford legitima a carga ideológica registrada em seu trabalho. Para uma consideração hermenêutica de sua obra, à ótica de Schleiermacher, com base também nos postulados de Lederer \& Seleskovitch (1989), os aspectos histórico-sociais ligados à gênese do texto conduzem ao período de tensões do pós-guerra, que culminaria nas rupturas acentuadas pelo Maio de 1968. Os Schtroumpfs

2 [un dictionnaire commencerait à partir du moment où il ne donnerait plus le sens mais les besognes des mots]. 
procuram pôr em evidência a igualdade dos seres na totalidade do cosmos, tomando a língua como bandeira.

Sob o prisma do leitor, manifesta-se um pequeno povo azul, pretensiosamente desvinculado das obrigações do dizer que, segundo Barthes (1980), tornam a língua simplesmente fascista, uma vez que ela "não permite dizer", mas "obriga a dizer". Culliford desfaz, em certo sentido, a imensa fé que geralmente se atribui à palavra. Assim, através de uma sequência de grafemas 〈schtrompf〉, compõe um morfema em potencial, mudo em significação, mas que recusa o silêncio. Um morfema aparentemente vazio, em estado latente, aguardando as orientações do leitor para assumir significação plena. Nas HQs, as lacunas permanecerão onde foram plotadas, como em qualquer texto, aguardando as novas interpretações de um novo leitor.

Como uma aldeia autônoma, o povo Schtroumpf não poderia deixar de ter sua língua $e$, por extensão, sua cultura própria. Todavia, as intenções pedagógicas de Culliford foram alteradas quando de suas traduções. A língua do pequeno povo azul foi simplesmente eliminada. Só puderam continuar desfrutando desta característica lúdica os leitores francófonos. O mergulho nas tramas linguísticas e semióticas presentes no original tornou-se impossivel para leitores de outras línguas. Do mesmo modo, sua investigação científica, à luz de teorias que sugerem a abordagem crítica com base em fatos de ordem cultural e histórica ficaria comprometida sem acesso ao original. A hermenêutica de Schleiermacher é retomada sob outros ângulos em Lederer e Seleskovitch (1989), Berman (1995), Toury (1995), Nord (1997), Even-Zohar (1990), porém mantendo os pressupostos básicos que apontam para a necessidade de considerar os polissistemas. Efetivamente, tanto a hermenêutica de Schleiermacher quanto os demais autores estabelecem que o ego, o hice o nunc do sujeito intérprete devem considerar o máximo de aspectos que permeiem a gênese do texto, como garantia para sua recriação. Algumas razões históricas e culturais sempre correm o risco de serem eliminadas por serem ignoradas.

Nesta investigação, busca-se, então, resgatar a proposta original de Culliford, demonstrando, na língua portuguesa, o traço principal que caracteriza o trabalho do artista. Assim, será possivel constatar que as tramas que se estabelecem internamente na parcela verbal ou nas relações verbo-imagéticas, e que viabilizam a instauração dos chamados falsos-gaps, são explicitamente intencionais. Estes conjuntos de trocas semióticas fazem emergir os diversos traços que caracterizam a chamada "língua dos estrunfes". Uma língua diegética no sentido estabelecido por 
Platão e Aristóteles, que contempla igualmente os pressupostos de composição do signo, tal qual definido por Saussure (2006/1916). O autor busca contemplar algumas das reflexões correntes da prática tradutória, tal como a atitude do leitor diante de uma palavra desconhecida. Sabe-se que nem sempre é necessário, possivel ou suficiente recorrer ao dicionário. Em algumas situações a habilidade de interpretação conduz à tradução pertinente para o contexto.

Durante a leitura das HQs dos Estrunfes, uma vez desveladas as significações aparentemente ocultas, formam-se unidades lexicais plenas. Por exemplo:

Estrunfei mal esta noite!

Efetivamente, a frase pouco informa. Todavia, quando se acrescenta determinada informação complementar, estrategicamente colocada, tal como a que segue sublinhada, imediatamente abrem-se leques para interpretações:

Estou com sono, estrunfei mal esta noite!

O "falso-gap" é então preenchido mais facilmente. Além disso, já no primeiro contato com a obra, constata-se que o universo dos Estrunfes é essencialmente tautológico, isto é, parte das pistas e soluções para definir as significações omitidas provém, concomitantemente, de componentes intra-textuais de natureza verbal e da parcela imagética. $O$ sentido da proposição, em muitos casos, já está explicitado na imagem. Os componentes imagéticos se traduzem em textos, mentalmente verbalizados, que dialogam com aqueles expressos através do verbo escrito.

Culliford recorre a estilo dialético singular, apanágio do artista que navega entre expressões estéticas plurais. Para tal, considera significações culturalmente convencionadas para cores, gestos, ícones, símbolos, etc. Diferentemente da dupla articulação proposta por André Martinet (1975), os componentes imagéticos não possuem relações sintáticas, socialmente compartilhadas, que permitam compará-los ao código linguístico (cf. GIRIBONE et. al., 1992). Todavia, a linearidade da arte sequencial permite que se preencham igualmente os gaps-imagéticos situados entre um quadro e outro. Logo, em uma cena que mostra a personagem saindo de sua casa, indo para o pomar, o leitor é capaz de imaginar toda a caminhada realizada no percurso entre um ponto e outro, verbalizando men- 
talmente, para si, o desenvolvimento progressivo e linear dos scripts não explicitados.

\section{Conversando com os Smurfs}

Em espanhol "Pitufos", em alemão "Chlümpfe", en italiano "Puffi", em português a denominação conhecida tem sua origem a partir da tradução da versão veiculada em língua inglesa. Quem, da geração dos anos 1980, não conhece Os Smurfs? As Histórias de Schtroumpfs foram traduzidas em mais de cem línguas diferentes. A série foi levada ao cinema e veiculada em vários países. Todavia, desprovida de sua verdadeira identidade.

De forma implícita, Culliford fala sobre a necessidade de diálogo sobre as diferenças expressamente assumidas após os grandes conflitos mundiais e, singularmente, durante as tensas acomodações políticas das décadas posteriores, no âmbito das quais lança sua obra (i.e. 1958). O espaço diegético das HQs conduzem o leitor a interagir na dimensão ficcional da trama e a expressar sua criatividade. $O$ patamar mimético também se faz presente e exerce o papel de speculum - isto é, de componente de reflexo e de especulação - a respeito de nossa própria sociedade. $O$ autor lança os germens que farão brotar o desejo de retorno aos valores básicos da existência humana. De fato, uma crítica, entre tantas outras, que conduziriam às rupturas desencadeadas a partir de 1968.

A antropologia marxista, sobretudo no que concerne à crítica ao sistema capitalista, se faz igualmente evidente, abrindo imensos leques para o exame de aspectos veiculados através da língua e também das imagens das HQs de Culliford. Componentes semióticos são minuciosamente colocados em espaços e pontos adequados, registrando significações profundas, sobre cores, formas e expressões verbais. $O$ vermelho, por exemplo, usado pelo chefe da tribo, define as filosofias políticas em voga naquele período histórico, no qual pairavam ideais comunistas. $O$ barrete frígio, ícone histórico das revoluções, reflete não somente ideologias subjacentes, mas também o compromisso com as representações históricas na composição da obra. Eventuais semelhanças não são meras coincidências. Elas apontam para a necessidade de uma sociedade mais justa. A língua dos Estrunfes abre possibilidades para o compartilhamento de aspectos comuns a todos os idiomas, no entanto, sem constituir apanágio de nenhum deles. 


\section{Redescobrindo os Estrunfes}

Uma sequência de caracteres que se repete. Uma raiz quase muda e, ao mesmo tempo, capaz de quase tudo exprimir. Em síntese, unidades lexicais aparentemente vazias, mas que constituem espécies de passepartout, unidades linguísticas prêt-à-porter, preparadas para gerar sintonias linguísticas em todas as situações em que aparecem e para as quais apontam.

Os processos de construção de sentido, a partir da leitura dos textos expressos em estrunfe, permitem compreender a aproximação entre línguas diferentes, a partir do momento em que a busca pela significação das palavras conduz à observância de todos os elementos que permeiam o discurso. Os processos de interpretação e de tradução, realizados a partir da confrontação de códigos linguísticos diferentes, equiparam-se, em muitos aspectos, àqueles realizados quando da troca de sentido entre modalidades semióticas distintas. Por exemplo, quando, apesar das lacunas presentes no texto, a significação de palavras e expressões se processa de modo pertinente, percebe-se o excessivo valor geralmente atribuído à forma em detrimento da significação. A partir desta constatação, como já afirmado, é possível questionar a imensa fé e o respeito concedidos à palavra, em suas denotações, conotações, associações e exemplos, geralmente fornecidos pelos dicionários normativos. $O$ discurso se eleva então à condição de suporte maior à interpretação do texto e, por extensão, para a posterior definição das significações locais e específicas, independentemente de seu caráter pleno ou de sua aparência vazia. Por isso chamado "falso-gap" no escopo deste estudo.

A troca de sentido entre modalidades semióticas, notadamente entre o texto e componentes imagéticos que marcam, de modo geral, o universo das HQs, torna o contexto dos Estrunfes essencialmente tautológico. Aquele que está de pé, diante de uma parede, com um pincel e uma lata de tinta nas mãos afirma:

Vou estrunfar esta parede de azul.

Na verdade, a proposição acima já está explicitada no texto imagético. A significação do verbo estrunfar já foi anteriormente definida através da imagem. $O$ contexto linguístico só vem corroborar a hipótese conhecida. Ademais, a sequencialidade da imagem, embora se desenvolva de forma bastante rudimentar, permite acumular informações a respeito dos 
traços que caracterizam as personagens (cf. GIRIBONE et. al., 1992). Quando o Estrunfe-Jardineiro, caracterizado por suas roupas e ferramentas de trabalho, sai para sua jornada diária e anuncia:

Preciso estrunfar as árvores do jardim.

- leitor interpreta de modo pertinente a situação e traduz de forma sensata a atividade que ele irá realizar, pois já possui sua interpretação dos fatos. Com efeito, a informação já havia sido fornecida através dos elementos imagéticos que compõem a cena.

Culliford lança, efetivamente, uma pequena semente, à primeira vista contraditória, isto é, uma sequência de caracteres que, ao mesmo tempo, "nada" e "tudo" significam. Em primeiro lugar, "nada", posto que isolada não constitui um morfema conforme propõe Martinet (1975), fora de contexto também não corresponde à noção de signo socialmente compartilhada, tal como estabelecida por Saussure (2006). A sequência não possui significação possível enquanto não se integrar à frase ou se submeter às transformações da língua de base que a acolhe. A sequência <schtroumpf〉 pertence ao vocabulário particular dos personagens que a empregam, representando inicialmente o nome próprio de todos eles. Em segundo lugar, "tudo", por estar apta a assumir as possíveis significações delineadas pelo contexto geral no qual se inserem. Essa sequência lacunar, de certa forma, parece contraditória por romper com os princípios básicos da dupla articulação da linguagem, segundo a qual os fonemas, concatenados, constituem morfemas que, por sua vez, se unem para formar palavras. Neste caso, pelo menos na raiz estrunf, há tão somente fonemas interligados, todo o resto é composto por significações a serem desveladas. A partir deste patamar, inicia-se o processo lúdico e pedagógico, ou seja, as manipulações explícitas do artista para tornar os jogos possíveis. Ajustes que permitem aos leitores interpretar e traduzir as lacunas assentadas no texto, sem recorrer ao dicionário, até porque este não existe, pois se fosse elaborado, seria composto por uma única entrada, porém, altamente polissêmica. O léxico lacunar da língua dos Estrunfes se atualizaria diante de cada uma de suas ocorrências, em função dos fenômenos idiossincrásicos, isto é, da recepção de cada leitor, a cada nova leitura.

Esta raiz fixa, que toma por base o próprio nome dos Estrunfes, segundo a língua de base sobre a qual se instala, pode receber uma série de componentes morfológicos e, assim, participar na composição de nomes, verbos, advérbios, provérbios, perífrases, etc. Exatamente os mes- 
mos componentes que participam na formação das entidades linguísticas dotadas de funções específicas no âmbito do discurso. Por exemplo:

Ele vai estrunfar na posição de goleiro no jogo de hoje à noite.

A adoção da desinência '-ar', da primeira conjugação do português, permite formar um verbo no infinitivo. Ademais, seu co-texto, isto é, sua posição na estrutura sintática da frase, bem como os traços semânticos que compõem as significações dos elementos anexos, permite definir perfeitamente a significação do verbo estrunfar.

A forma verbal canônica, expressa pelo infinitivo, pode, naturalmente, se flexionar de acordo com as formas previstas na língua portuguesa. Além de formar unidades lexicais, os falsos-gaps se integram ao discurso de modo manipulado. Logo, não geram quaisquer prejuízos à composição do sentido dos textos, uma vez que são facilmente decifráveis. Pelo contrário, promovem a reflexão e induzem ao exercício de interpretação e de tradução.

O leitor, ao constatar a possibilidade de encontrar a significação de uma palavra que desconhece, passa a desenvolver maior grau de confiança em relação ao desenvolvimento da capacidade de dedução. Por meio de tomadas de decisões autônomas diante de dificuldades de natureza linguística, supõe-se que o leitor jovem passaria a não se intimidar diante de léxico desconhecido quando da leitura dos textos. Naturalmente, diferentemente daquilo que ocorre em situações ditas "reais", nas HQs dos Estrunfes, os fenômenos são precisamente previstos e controlados, mas não diminuem seu caráter pedagógico. Ademais, a interpretação e a tradução se apresentam como uma atividade lúdica.

\section{Mais vale um estrunfe na mão que dois voando}

Provérbio criado no período da sociedade tipicamente rural, a expressão metafórica apresentada no subtítulo acima continua permeando as mudanças sociais. Eventuais flutuações em sua significação não impedem que o falso-gap seja facilmente preenchido. Há, na verdade, em todas as línguas, grande número de estruturas fixas que se conservam por longos períodos. No caso da língua dos Estrunfes, a noção de unidade composta vai muito além dos provérbios, pois uma alta recorrência é suficiente para que o fenômeno se instale. Logo, frases como a apresentada abai- 
xo, embora não sejam consideradas provérbio, constituem expressão quase fixa, viabilizando a recuperação de informações omitidas de modo instantâneo. Nenhum leitor terá dificuldade para interpretar as informações aparentemente omitidas:

É estrunfamente proibido estrunfar sem carteira de motorista (advérbio e verbo).

Todos esses jogos, que caracterizam o falar-estrunfe, como já mencionado, são realizados com base no sistema da língua de base que os acoThe. Nesse sentido, as implicações morfológicas, sintáticas, semânticas e pragmáticas, enfim, os componentes do discurso como um todo, são aquelas consideradas, por exemplo, nas análises formais da língua. As relações entre a expressão verbal e a imagem também imitam os processos inerentes à expressão verbal efetiva, isto é, a língua em uso.

A particularidade empregada por Culliford em sua obra não é produto de seu gênio. Jogos sobre a língua, segundo Yaguello (1981) são tão antigos quanto sua história. Por exemplo, na fala cotidiana, nas brincadeiras com a língua, o verbo coisar, ou nomes como troço, negócio, coisa, o trem (mineiro) apoiam a decifração de suas significações nos co-textos, nos contextos semântico-pragmáticos e discursivos. Efetivamente, como no falar-estrunfe, estamos diante de falsos-gaps. Assim, a frase abaixo não se torna totalmente absurda. Sua tradução, no entanto, exigiria recurso ao contexto situacional:

Para furar essa coisa preciso de um troço pontudo.

Diante de uma imagem de alguém tentando perfurar um coco verde para extrair a água e a polpa, qualquer leitor seria capaz de desambiguizar os entroncamentos criados pelas unidades sublinhadas. Evidentemente, tais unidades não constituem uma língua. São recursos que permitem reduzir a pluralidade inerente à composição do léxico. Na verdade, os Estrunfes não possuem uma língua. Tal denominação se adapta, no entanto, ao universo da arte aqui abordada. Uma fantasia que parece pueril, mas que reflete posicionamentos sérios, posto que participam na formação de representações e identidades do público leitor. 


\section{Considerações finais}

O falar-estrunfe se desenvolve em ambiente essencialmente dialético, no qual o leitor é convidado a recusar não somente o silêncio, mas também a fé e o respeito concedidos às palavras. Segundo George Bataille (1929), a significação não está atrelada à forma e, conforme Brito (2003), muito menos à forma que nos obriga a dizer. A significação deve responder às necessidades que se tem da palavra e a forma se completa. Nesse sentido, nos usos artísticos e literários, de acordo com Barthes (1980), as palavras se libertam das relações biunivocas entre forma e significação que, em muitos casos, garantem a manutenção dos poderes. A postura de Culliford busca conciliar preceitos estruturalistas ligados à forma, com as funções da língua e das linguagens.

O falar-estrunfe abala os percursos etimológicos e as heranças ideológicas que pesam sobre as conotações, as denotações, as associações e os exemplos presentes nos escritos normativos, resultado de longos percursos sociais e cristalizados na língua. As obrigações de dizer, assumidas no processo de apropriação de qualquer língua, são colocadas em questão, abrindo vários leques para interpretações e análises críticas. As HQs de Culliford projetam certa liberdade de expressão. Uma democracia linguística situada num espaço de diálogo, no qual a relação entre forma e significação foge às prescrições clássicas.

As atividades com os Estrunfes atraem a atenção do leitor sobre a necessidade de evidenciar o sentido de palavras desconhecidas. Os indícios plotados na parcela textual, bem como na porção visual, permitem definir estratégias de leitura. O leitor poderá recorrer aos seus próprios saberes para realizar suas inferências. Tal fato o lança no meio da trama, exige sua participação, como se estivesse ao lado das personagens.

Não se trata, absolutamente, de exigir que o leitor encontre a "fórmula correta", pois não há uma única resposta para os falsos-gaps. O objetivo maior não se encontra no fim, mas no processo e nos recursos adotados para buscar significações que preservem a coesão e a coerência dos textos. Finalmente, a tradução do falar-estrunfe parece remeter à arte dos copistas e dos escribas de todos os tempos, que muitas vezes se dividiam entre o desenho da letra e o desenho das imagens, buscando estabelecer diálogo entre os dois patamares. 


\section{Referências}

BARTHES, Roland. Aula, tradução de Leyla Perrone-Moisés. São Paulo: Editora Cultrix, 1980.

BATAILLE, Georges. Documents. Paris: №07, Décembre de 1929.

BERMAN, Antoine. Pour une critique des traductions: John Donne. Paris: Gallimard, 1995.

BRITTO, Luiz Percival Leme. "Língua e Ideologia". In: BAGNO, Marcos (org.) Lingüística da Norma. São Paulo: Ed. Loyola, 2003.

COELHO, Nelly Novaes. Panorama Histórico da Literatura Infantil/Juvenil. São Paulo: Ática, 1991.

CULLIFORD, Pierre. Histoires de Schtroumpfs par Payo. Bruxelles/ Belgique: Ed. Cartoon Creations, 1980/1958.

ECO, Umberto. Sette anni di desiderio. Bologna/Itália: Tascabili Bompiani, 2000.

EVEN-ZOHAR, Itamar. "Poetics today". In: Polysystem studies. Tel Aviv: Vol. 11, №. 1, 1990. pp. 9-78.

GIRIBONE, Jean-Luc; DUPUY, Jean-Pierre; MONGIN, Olivier. Groupe $\mu$ - Traité du signe visuel - Pour une rhétorique de l'image. Paris: Seuil, 1992. LEDERER, Marianne \& SELESKOVITCH, Danica. "The Interpretation Process". In: A Systematic Approach to Teaching Interpretation. Paris: European Communities, 1989.

LIMA, Ronaldo \& SCHRULL, Munique. Os Schtroumpfs na literatura infanto-juvenil. Anais do VIII Seminário Internacional de História da Literatura. Porto Alegre: PUC, 2009.

MCCLOUD, Scott. Desenhando os quadrinhos. São Paulo: Makron Books, 1995.

Reinventando os quadrinhos. São Paulo: Makron Books, 2006.

Desvendando os quadrinhos. São Paulo: Makron Books, 2008.

MARTINET, André. Elementos de lingüística geral, tradução de Jorge Morais Barbosa. São Paulo: Martins Fontes, 1975. 6a. Ed. Cap. 1 (pp. 1-24); Cap. 6 (pp. 175-213).

NORD, Christiane. Functionalist Approaches Explained. Manchester, UK: St. Jerome Publishing, 1997.

SAUSSURE, Ferdinand de. Curso de lingüística geral. São Paulo: Cultrix, 2006/1916. 
SELESKOVITCH, Danica. \& LEDERER, Marianne. Interpréter pour Traduire. Paris: Didier, 1984.

SWIFT, Jonathan. As aventuras de Gulliver, adaptação de Karine Gonçalves. São Paulo: Impala, 1996/1726.

TOURY, Gideon. Descriptive Translation Studies and beyond. Amsterdam: John Benjamins, 1995.

YAGUELLO, Marina. Alice au pays du langage: pour comprendre la linguistique. Paris: Seuil, 1981. 